This is a postprint version of the following published document:

Crespo, M., González, M. y Pozuelo, J. (2014): Magnetic silica:epoxy composites with a nano- and micro-scale control. Materials Chemistry and Physics, 144 (3), pp.: 335-342.

DOI: 10.1016/j.matchemphys.2013.12.049

(C) Elsevier, 2014

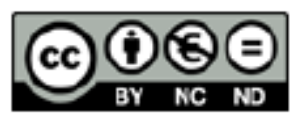

This work is licensed under a Creative Commons Attribution-NonCommercialNoDerivatives 4.0 International License. 


\title{
Magnetic silica:epoxy composites with a nano- and micro-scale control
}

\author{
María Crespo, María González, Javier Pozuelo* \\ Departamento de Ciencia e Ingeniería de Materiales e Ingeniería Química (IAAB), Universidad Carlos III de Madrid, 28911 Leganés, Madrid, Spain
}

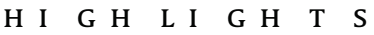

- We present a strategy that permits the nanoscale and micro scale con trol through a simple protocol.

- $\mathrm{Cu} \mathrm{Ni}$ ferrites were prepared into the structure pores if commercial silica with a size control by annealing temperature.

- $\quad$ Composites with epoxy matrix were prepared.
\end{abstract}

The reinforcements provided an increase in glass transition temperature and decomposition temperature of the composites.

G $\quad$ R A A P $\quad$ P I I C A L A B S S T R A C T

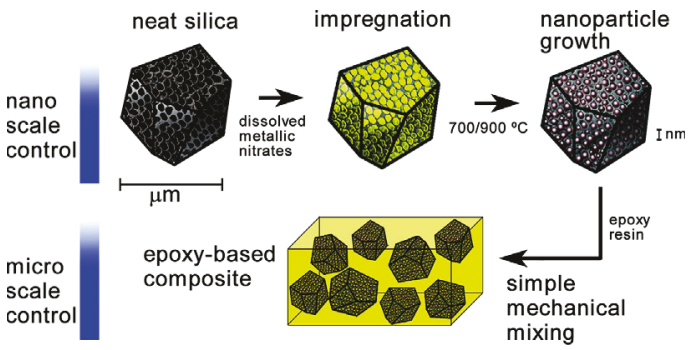

KEYWORDS

Magnetic materials

Nanostructures

Thermal properties

Microporous materials
Multiscale composites with magnetic properties were prepared by incorporating $\mathrm{Cu} \mathrm{Ni}$ nanoferrites filled silica microparticles in an epoxy matrix. The size of the nanoferrites was controlled both by the structure of the silica template and the annealing temperature (700 and $900{ }^{\circ} \mathrm{C}$ ) used during the syn thesis procedure. The ferrite:silica particles prepared at $700{ }^{\circ} \mathrm{C}$ showed a narrow size distribution close to $8.3 \mathrm{~nm}$ with a superparamagnetic behaviour. A less symmetric size distribution was obtained when annealing was performed at $900^{\circ} \mathrm{C}$, with diameters ranging from 15 to $80 \mathrm{~nm}$. The reinforcement incorporation increased up to $7{ }^{\circ} \mathrm{C}$ the glass transition temperature and $30{ }^{\circ} \mathrm{C}$ the decomposition tem peratures of the composites. The proposed strategy permits the nanoscale control, by the trapping effect of the silica on the magnetic nanoparticles, as well as the control of the micro scale distribution through a simple protocol. These composites could have potential applicability as EMI shielding materials, owing to their magnetic nature, lightweight and enhanced thermal stability.

\section{Introduction}

Research on materials with specific functional properties is an active field nowadays. Combining low density polymers with nanoparticles seems to be a good strategy to transfer the properties of the reinforcement (mechanical, electrical, magnetic, thermal, etc) to the global material. For example, improved electrical and mechanical properties have been achieved when introducing small amounts of carbon nanotubes in polymer matrices [1,2], epoxies loaded with nano and micro silica particles have shown enhanced mechanical properties and wear resistance $[3,4]$, and multifunc tional nanostructured core-shell magnetic nanoparticles having giant magnetoresistance sensing ability or microwave absorption properties [5] could lead to composites with potential applications as magneto optical modulators [6], biocompatible membranes for sensing [7] or as electromagnetic (EMI) shielding materials [8] when embedded in polymer matrices. 
In all cases, the properties of the nanocomposites seem to depend mainly on the aspect ratio of the particles and their dispersion degree in the matrix. Thus, two main aspects must be controlled when designing such materials: the size and shape of nanoparticles and the homogeneity of their dispersion. For mag netic particles, the size of the magnetic domains and its dispersion will strongly determine the magnetic properties of the final ma terial, e.g. soft or hard magnetic behaviour [9]. Thus, in order to achieve monodomain superparamagnetic nanoparticles, it is essential to avoid the coalescence of nanoparticles during its growth and to restrict their maximal dimensions [10].

The synthesis of size controlled magnetic nanoparticles within polymer matrixes may be accomplished either by in situ poly merization while particle formation $[9,11]$ or by dispersing pre formed magnetic nanoparticles in the polymer matrix. In this latter case, many routes for synthesizing size controlled nanoparticles involve the use of capping agents [12], precipitation in reverse microemulsions [13], or sol-gel processing [14] to avoid the coa lescence and further growth of the particles. But, since geometry is also important, other methods that allow the synthesis of shape controlled particles are being explored [15]. Nanocasting is a use ful technique that involves using a template (either soft or hard) which is impregnated by liquid precursors of the particles [16]. Finally, homogeneously dispersed nanoparticles within the tem plate are obtained as the negative image of it. Silica is may be the most widely used hard template, since its geometry is stable and can be obtained with different pore shapes and sizes via sol-gel [17]. Nanocasting using hard templates has been successfully employed for the preparation of ferrites with several transition metals as $\mathrm{Cu}, \mathrm{Co}, \mathrm{Ni}, \mathrm{Pd}, \mathrm{Zn}$ [18-21]. Ferrites have attracted much attention in EMI shielding applications because of their strong magnetic losses [22]. The electromagnetic absorption process by magnetic particles induces magnetic spin rotation and the mag netic energy can be dissipated by heat transfer to the matrix. This mechanism could be the most appropriate for protecting the in ternal elements of electronic devices. Among spinel ferrites, inverse spinels are particularly interesting because of their high magne tocrystalline anisotropy and permeability. Ni ferrites correspond to these types of ferrites and their substituted counterparts have shown increased attention due to their promising high frequency applications [23]. Moreover, Cu Ferrites have shown enhanced thermal, magnetic and dielectric properties [24,25] and its substi tution with $\mathrm{Ni}$, e.g. $\mathrm{Cu}_{1-x} \mathrm{Ni}_{x} \mathrm{Fe}_{2} \mathrm{O}_{4}$, has lead to EMI shielding ma terials having the maximum reflection loss ( $25 \mathrm{~dB}$ ) for the composition of $x \quad 0.5$ [26].

However, ferrites are quite heavy and, although promising re sults have been published, EMI shielding materials are advocated to find lighter counterparts that may replace heavy, nor easily pro cessable or chemically resistant materials that have been tradi tionally used as microwave shields/absorbers. Consequently, for this application, polymer based composites, having low densities, are attractive matrixes for the incorporation of high magnetic loss constituents. Ferrite powders mixed with non magnetic polymers have been proposed as tentative materials that may overcome the high frequency loss that ferrites, by themselves, present at fre quencies above $100 \mathrm{MHz}$, enabling their use in electromagnetic absorption applications even at $\mathrm{GHz}$ range [27].

Preparation and characterization of nanocomposites by incor poration of magnetic nanoparticles within thermosetting polymers has been pursued by different approaches [28-31], and, in most cases, being able to disperse the nanoparticles remains challenging since their high surface energy favours agglomeration [32,33] even at low loadings. To overcome this problem several routes have been proposed, such as surface modification of the nanoparticles, which is expected to improve nanoparticle-polymer matrix interactions either through weak Van der Waals interactions or strong chemical bonds [34,35]. Silica coated magnetic nanoparticles have also been proposed as an alternative to increase compatibility and to avoid further oxidation of the particles [36,37]. Additionally, enhanced EMI shielding of such core-shell type structures has been reported, owing to multiple interfacial polarization mechanisms and to a better impedance matching due to the unique structure of silica [38,39].

Though all these promising findings, as it was mentioned pre viously, dispersing inclusions having nanometric sizes is physically unfavourable even having the best possible scenario. High energy mixing techniques are necessary and time consuming surface modifications are still needed to partially overcome nanoparticle agglomeration. To circumvent this situation and still being able to combine the specific properties of individual magnetic nano particles with the lightweight of polymers, a possible approach could be to pre disperse the nanoparticles inside micron sized porous particles, which are by far more easily dispersible in poly mers. Inclusion of magnetic nanoparticles within micron sized mesoporous silica has diverse applications such as separation of biomolecules [40], adsorption of pollutants in water [41] and as catalysts for chemical reactions [42], although, as far as our knowledge, no preparation of polymer based composites has been reported with this type of hybrid structures. Moreover, this type of combination could eventually lead to strengthened multifunctional polymer based materials, besides magnetism, as it has been re ported that pristine porous micron sized silica improves the me chanical properties (fracture toughness, modulus, and deformation at break) of polymer based composites [43,44] and increased thermal stability is also expected. Besides, when considering magnetically loaded polymer composites for EMI shielding, it is well established that electromagnetic absorbers dissipate electro magnetic energy into heat and thus, materials which combine enhanced thermal stability, magnetic activity and lightweight, could be prospective candidates for this application.

In this work a high surface micron sized silica template has been selected as host structure of magnetic CuNi ferrite nanoparticles. The hybrid silica-ferrite material has been synthesized by a simple and cheap nanocasting procedure that enables the homogeneous and individual spatial distribution of the magnetic cores within the silica pores. The hybrid micro reinforcement has been homoge neously dispersed in an epoxy resin by low energy mixing while the ferrite nanoparticles remained unaltered within the micron sized silica particles. The employed strategy permits to disperse magnetic nanoparticles in an epoxy matrix in a simplified way due to the fact that they are already dispersed within easily dispersible micron sized silica particles. The prepared composites could have potential applicability as EMI shielding materials, owing to their magnetic nature, lightweight and enhanced thermal stability.

\section{Materials and methods}

\subsection{Synthesis of nanoparticles and preparation of composites}

$\mathrm{Cu}_{0.5} \mathrm{Ni}_{0.5} \mathrm{Fe}_{2} \mathrm{O}_{4}$ ferrite nanoparticles were synthesized using silica gel (Aldrich Ref. 288500 , particle size: $2-25 \mu \mathrm{m}$ and pore size: $60 \AA$ ) as hard template. The general casting procedure developed by Fuertes et al. was followed [21]. Appropriate amounts of $\mathrm{Fe}\left(\mathrm{NO}_{3}\right)_{3} \cdot 9 \mathrm{H}_{2} \mathrm{O}, \mathrm{Ni}\left(\mathrm{NO}_{3}\right)_{2} \cdot 6 \mathrm{H}_{2} \mathrm{O}$ and $\mathrm{Cu}\left(\mathrm{NO}_{3}\right)_{2} \cdot 2.5 \mathrm{H}_{2} \mathrm{O}$ (purchased from Sigma Aldrich) were mixed in order to get a $\mathrm{Cu}$ :Ni:Fe ratio of $1: 1: 4$. The nitrates were dissolved in $16 \mathrm{~g}$ of ethanol and the solu tion was used for impregnating the silica gel. The wet nitrate-silica was dried at $90^{\circ} \mathrm{C}$ overnight and the impregnation-drying process was repeated once in order to increase the metal ion content inside the silica pores. The thermal decomposition of the nitrates was 
carried out in an electric furnace, using $\mathrm{N}_{2}$ as inert atmosphere, for $4 \mathrm{~h}$ at $700{ }^{\circ} \mathrm{C}$ or $900{ }^{\circ} \mathrm{C}$ using a $5{ }^{\circ} \mathrm{C}$ min $^{-1}$ heating ramp.

Epoxy matrix composites were prepared using HexFlow ${ }^{\circledR}$ RTM 6 monocomponent epoxy formulation (supplied by Hexcel Corpora tion). The chemical structure of the key constituents of the RTM6 epoxy resin [45] are depicted in Fig. 1. The nanoferrite filled silica particles were added to the resin, mechanically stirred for $15 \mathrm{~min}$ at 80-90 ${ }^{\circ} \mathrm{C}$ and degassed in vacuum. The mixtures with different filler content $(10,15,20$ and $25 \% \mathrm{w} / \mathrm{w})$ were poured into pre heated silicone mould $\left(120^{\circ} \mathrm{C}\right)$ and cured $75 \mathrm{~min}$ at $160{ }^{\circ} \mathrm{C}$ and $120 \mathrm{~min}$ at $180^{\circ} \mathrm{C}$.

For Transmission Electron Microscopy (TEM) images, the ferrite nanoparticles were subjected to detemplation by stirring the fer rite:silica powders in a $2 \mathrm{M} \mathrm{NaOH}$ solution for $24 \mathrm{~h}$. The as prepared particles were then dispersed in an ammonium solution of $\mathrm{pH}$ 910 , placed in an ultrasonic bath at $70-80{ }^{\circ} \mathrm{C}$ and oleic acid was added until $\mathrm{pH} 7$ was reached. The oleic acid coated nanoparticles were then rinsed several times with acetone and hot water to remove the excess of oleic acid, and collected afterwards using a magnet. To ensure the preservation of the nanoparticles after the basic treatment, the selected area electron diffraction (SAED) pat terns of the samples were recorded and contrasted to the powder $\mathrm{X}$ ray Diffraction patterns of the samples prior to detemplation.

\subsection{Characterization techniques}

The crystalline structure of the mixed ferrites was characterized by Wide Angle X ray Diffraction (XRD) on a Panalytical X'pert Pro $\mathrm{X}$ ray diffractometer with $\mathrm{Cu} \mathrm{K} \alpha$ radiation $(\lambda \quad 0.15406 \mathrm{~nm})$ ). Transmission Electron Microscopy (TEM) and High Resolution TEM (HRTEM) images of detemplated ferrite nanoparticles, were ob tained on a Philips Tecnai microscope at $200 \mathrm{kV}$. Both the pores of the silica template and the ferrite filled silica were characterized by nitrogen adsorption at $77 \mathrm{~K}$ on a Micrometrics Instrument Corp. Gemini VII 2390. The samples were previously degassed for $1 \mathrm{~h}$ at $363 \mathrm{~K}$ and $2 \mathrm{~h}$ at $423 \mathrm{~K}$. The surface area was determined using the Brunauer-Emmet-Teller (BET) method from 0.05 to 0.25 relative pressures. The pore size distribution was determined using desorption branch and the Barret-Joyner-Haelender (BJH) method. The total pore volume was measured at $P / P_{0} \quad 0.99$.

The magnetic properties of the particles were investigated by Vibrating Sample Magnetometry (VSM) at $300 \mathrm{~K}$ with a $10 \mathrm{~T}$ magnetic field. The coercitivity $\left(H_{\mathrm{c}}\right)$ and remanence values $\left(M_{\mathrm{r}}\right)$ were obtained from the hysteresis loops. The saturation magneti zation $\left(M_{\mathrm{s}}\right)$ values were obtained by extrapolating the magnetiza tion in the linear portion observed at high fields. Morphology of the composites was characterized by Scanning Electron Microscopy, on a Philips XL30 microscope operating at $15 \mathrm{kV}$.<smiles>c1cc(N(C2CO2)C2CO2)ccc1Cc1ccc(N(C2CO2)C2CO2)cc1</smiles>

Tetraglycidyl methylene diamine<smiles>Cc1cc(Cc2cc(C)c(N)c(C)c2)cc(C)c1N</smiles><smiles>Cc1cc(Cc2cc(C)c(N)c(C(C)C)c2)cc(C(C)C)c1N</smiles>

4,4'-Methylene bis(2-isopropyl-6-methylniline)

4,4'-Methylene bis(2,6-diethylamine)

Fig. 1. Chemical structure of the key constituents of RTM 6 formulation.
Thermal transitions were studied by Differential Scanning Calorimetry (DSC) on a Mettler Toledo 822 equipment, from 40 to $240{ }^{\circ} \mathrm{C}$ at $10{ }^{\circ} \mathrm{C} \mathrm{min}^{-1}$. The glass transition temperature was determined at the inflexion point of the recorded thermograms. Thermogravimetric Analysis (TGA) from $40{ }^{\circ} \mathrm{C}$ to $900{ }^{\circ} \mathrm{C}$ at $10^{\circ} \mathrm{C} \mathrm{min}^{-1}$ was made under air atmosphere, on a Perkin Elmer STA 6000 instrument.

\section{Results and discussion}

\subsection{Ferrite:silica particles and ferrite nanoparticles characterization}

The XRD patterns of the $\mathrm{Cu}_{0.5} \mathrm{Ni}_{0.5} \mathrm{Fe}_{2} \mathrm{O}_{4}$ ferrite nanoparticles synthesized within the silica template at $700{ }^{\circ} \mathrm{C}$ and $900{ }^{\circ} \mathrm{C}$ are shown in Fig. 2. Annealing temperature was varied in order to evaluate its role when controlling the size of the magnetic nano particles even if these were constrained inside the silica template. In both cases peaks at $2 \theta^{\circ} \quad 30.2,35.6,43.5,53.8,57.4$ and 63.0 were observed. These signals can be attributed to the (220), (311), (400), (422), (511) and (440) crystalline planes of a single phase cubic inverse spinel structure. The broad band at $2 \theta \approx 20^{\circ}$ corre sponds to the amorphous silica, which also shows a small crystal line contribution, probably related with small amounts of diatoms (cristoballite syn, trydimite syn, quartz), occurring in natural silica [46]. Diffraction peaks became sharper when the annealing tem perature was increased, thus involving a higher crystallization de gree without structural changes in the spinel. The crystallite size was determined using Scherrer's equation:

$$
D \quad \frac{k \lambda}{B \cos \theta}
$$

where $k \quad 0.9$ was used as shape factor, $\lambda$ is the radiation wave length and $B$ the width at half height of the diffraction signal, expressed in radians. According to this equation, and considering the plane (311), the crystal size of the ferrites synthesized at $700{ }^{\circ} \mathrm{C}$ and $900{ }^{\circ} \mathrm{C}$ are $8.6 \mathrm{~nm}$ and $23.8 \mathrm{~nm}$ respectively. The increase of crystal size with temperature could be a consequence of the enhanced diffusion at high temperatures or of a slight change in the template's pore structure when treated at $900{ }^{\circ} \mathrm{C}[47,48]$.

The size of the detemplated nanoparticles was further investi gated by TEM. Fig. 3 shows representative TEM images of the $\mathrm{Cu}-\mathrm{Ni}$ ferrite nanoparticles annealed at $700{ }^{\circ} \mathrm{C}$ and $900{ }^{\circ} \mathrm{C}$. Size

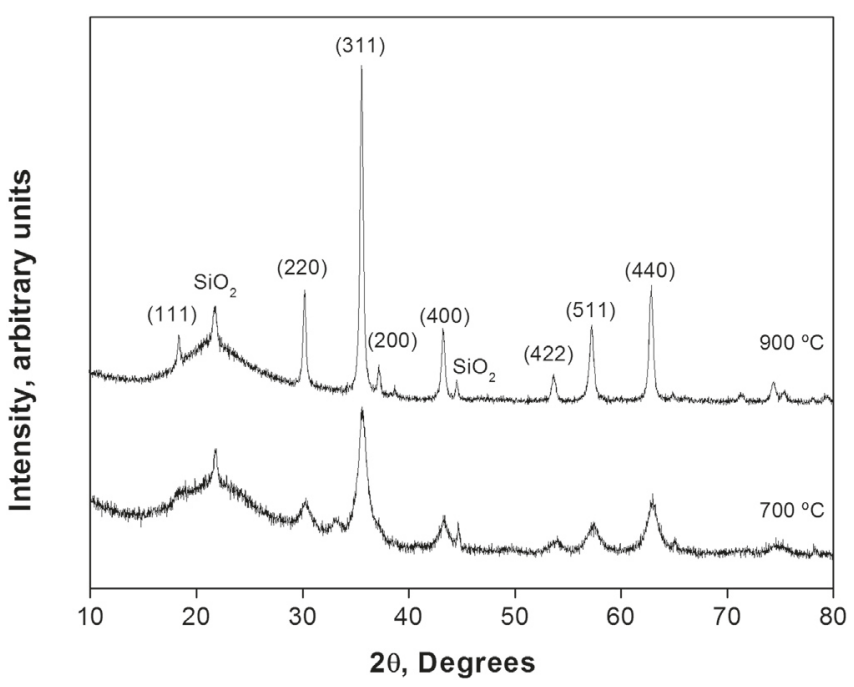

Fig. 2. X-ray diffraction patterns of the ferrite:silica material annealed at 700 and $900{ }^{\circ} \mathrm{C}$. 
distributions were determined by measuring the diameter of more than 190 particles in both cases. When annealing is done at $700{ }^{\circ} \mathrm{C}$, a narrow size distribution with an average particle size of $8.3 \pm 1.6 \mathrm{~nm}$ was observed; at $900{ }^{\circ} \mathrm{C}$, the particles showed a broader and less symmetric size distribution, with diameters ranging from 15 to $80 \mathrm{~nm}$. Such increase in the particle size, with the annealing temperature is in accordance with XRD observations. Moreover, SAED patterns taken by TEM, further confirmed the ex pected crystal structure for the nanosized ferrites which are in well agreement with the recorded powder $\mathrm{X}$ ray diffraction patterns and can be assessed as the typical diffraction rings observed for spinel structures (Fig. 3). It is worthy to note that the ferrites were detemplated only for being able to check, with a better contrast, their morphology. Furthermore, the agreement between the SAED and powder $\mathrm{X}$ ray diffraction patterns together with the measured particle size before (by powder $X$ ray diffraction) and after (by TEM) detemplation, confirm that no changes occurred during the treatment with $\mathrm{NaOH}$.

For evaluating the distribution of the ferrite nanoparticles inside the silica template, nitrogen adsorption-desorption isotherms were recorded for the pristine silica and the ferrite:silica materials

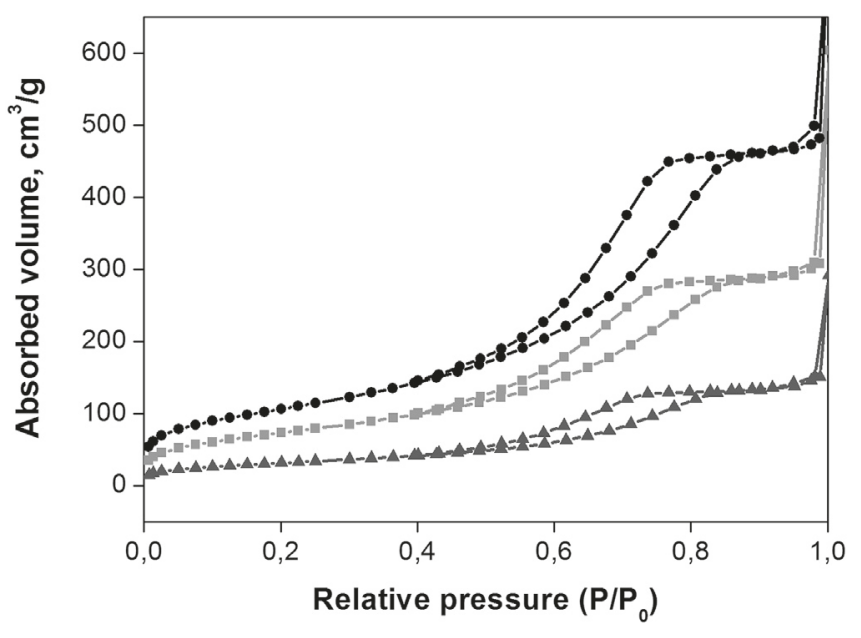

Fig. 4. Nitrogen adsorption desorption isotherms for the prepared materials, neat silica (- -), ferrite:silica, annealed at $700{ }^{\circ} \mathrm{C}(-\mathbf{-}-)$ and at $900{ }^{\circ} \mathrm{C}(-\mathbf{\Delta}-)$.
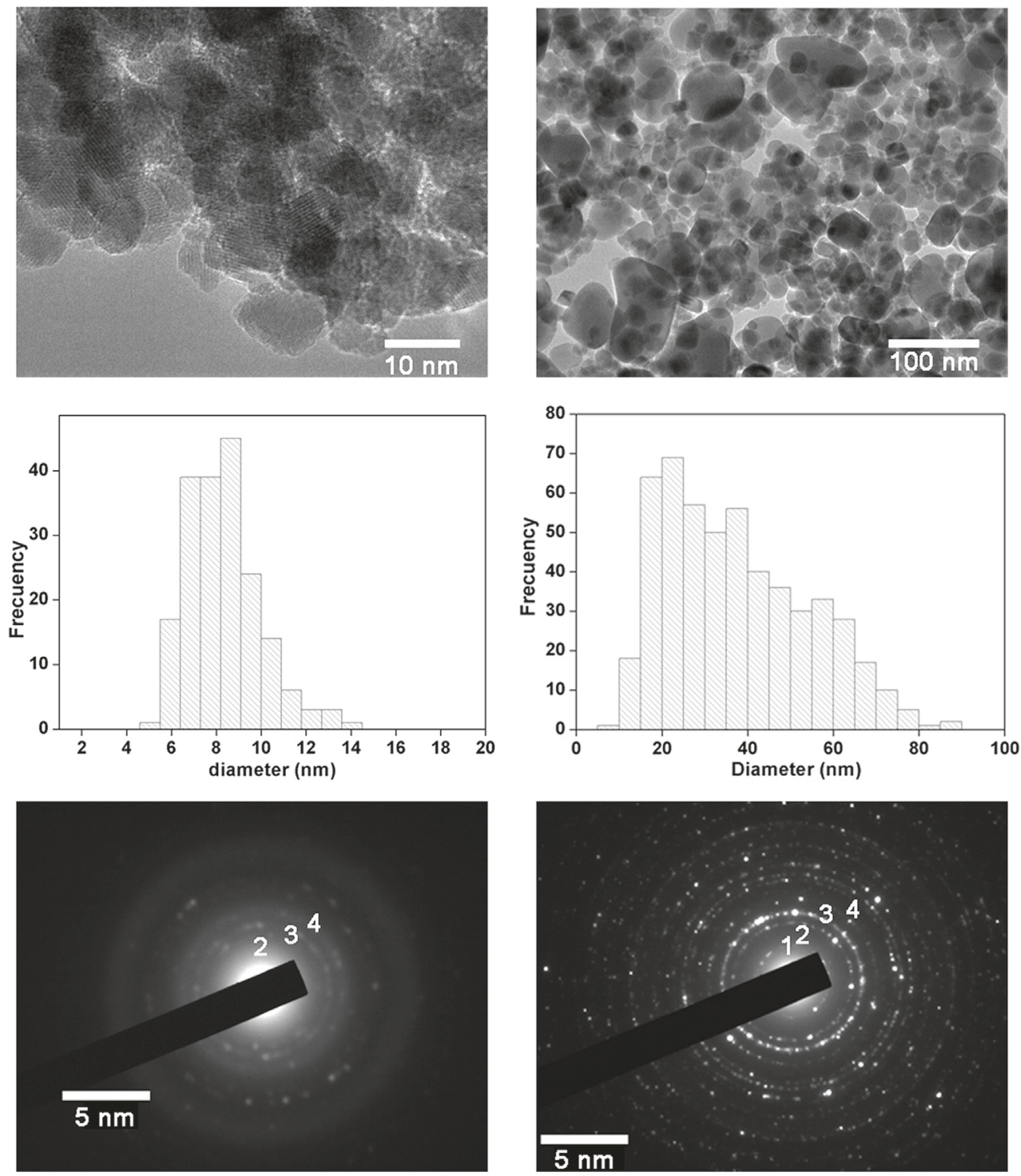

Fig. 3. HRTEM (top), particle distribution (middle) and electron diffraction patterns (bottom) of the Cu Ni ferrite nanoparticles annealed at $700{ }^{\circ} \mathrm{C}$ (left) and $900{ }^{\circ} \mathrm{C}$ (right). 
(Fig. 4). All the curves showed the typical hysteresis loop of mes oporous materials (type IV isotherm) where the closure at $P / P_{0} \sim 0.4$ indicates presence of small mesopores. No steep changes in the adsorption behaviour were observed at low relative pressures, indicating the absence of micropores in the system. This observa tion was further confirmed using the $t$ plot method for the specific surface area of micropores. The surface area, total pore volume and diameter for all the prepared materials are shown in Table 1, where the corresponding data for the silica without any ferrite loading, annealed at both temperatures $\left(700\right.$ and $\left.900{ }^{\circ} \mathrm{C}\right)$, are also shown. It can be seen that the surface area sharply decreases when comparing the neat silica with ferrite loaded materials, thus proving the filling of the pores. Moreover, there can be seen a decrease of this value arising solely from the thermal treatment. It has been previously reported that silica can undergo densification above $650{ }^{\circ} \mathrm{C}$ [49] related with the condensation of silanol groups from different particles or the rearrangement of primary particles in a denser array [50], effect that is more relevant for the ferrite: silica hybrid material treated at the highest temperature $\left(900{ }^{\circ} \mathrm{C}\right)$, where a reduction of $38 \%$ in the surface area was observed.

Regarding the total pore volume and the pore diameter, the synthesis of non porous inclusions in the pores reduces the porosity of the silica and consequently slightly the pore size, indi cating that the as grown particles are bulky and that they block (at least partially) some of the pores of the silica as observed for other guest transition metals oxides and carbons [51]. The small reduc tion of the pore diameter when compared with the surface area or total pore volume may indicate a non homogenous filling of the pores within the whole template structure [52].

The magnetic characterization of the ferrite:silica materials (Fig. 5) shows the field dependence of the magnetization of the samples annealed at $700{ }^{\circ} \mathrm{C}$ and $900^{\circ} \mathrm{C}$. The coercitivity, remanence and saturation magnetization were $10 \mathrm{Oe}, 0.06 \mathrm{emu}^{-1}$ and $4.06 \mathrm{emu} \mathrm{g}^{-1}$ respectively, for the sample annealed at $700{ }^{\circ} \mathrm{C}$ and $86 \mathrm{Oe}, 1.27 \mathrm{emu}^{-1}$ and $7.47 \mathrm{emu} \mathrm{g}^{-1}$ for the sample annealed at $900{ }^{\circ} \mathrm{C}$. These results arise from a nearly superparamagnetic behaviour with a hysteresis loss close to zero for particles prepared at $700{ }^{\circ} \mathrm{C}$, indicating that these nanoparticles are individual mon odomains dispersed inside the silica pores. The increase of the hysteresis losses with the annealing temperature may be a conse quence of the particle size growth [53]. It is worthy to note that both particles, annealed at $700{ }^{\circ} \mathrm{C}$ and at $900{ }^{\circ} \mathrm{C}$, were clearly attracted by a magnet, even though the calculated concentration of ferrite nanoparticles in the template is $\approx 23 \%(\mathrm{w} / \mathrm{w})$. Taking into account the proportion of magnetic constituent in the non magnetic silica material, the saturation magnetizations herein re ported are in well agreement with reported values for bulk $\mathrm{Cu}_{0.5} \mathrm{Ni}_{0.5} \mathrm{Fe}_{2} \mathrm{O}_{4}[54]$.

\subsection{Characterization of epoxy based composites}

Composites containing 10, 15, 20 and 25\% w/w of ferrite:silica particles were prepared and its morphology was observed by SEM.

Table 1

Surface area $(a)$, total pore volume $(v)$ and pore diameters $\left(\Phi_{\text {pore }}\right)$ obtained from the adsorption isotherms.

\begin{tabular}{llll}
\hline Sample & $a, \mathrm{~m}^{2} \mathrm{~g}^{1}$ & $v, \mathrm{~cm}^{3} \mathrm{~g}^{1 \mathrm{a}}$ & $\Phi_{\text {pore }}, \mathrm{nm}^{\mathrm{b}}$ \\
\hline Neat silica & 385.12 & 0.722 & 6.2 \\
Silica $700{ }^{\circ} \mathrm{C}$ & 367.68 & 0.648 & 6.1 \\
Silica $900{ }^{\circ} \mathrm{C}$ & 240.63 & 0.411 & 5.8 \\
Ferrite:silica $\left(700{ }^{\circ} \mathrm{C}\right)$ & 269.34 & 0.451 & 5.9 \\
Ferrite:silica $\left(900{ }^{\circ} \mathrm{C}\right)$ & 114.77 & 0.222 & 5.8 \\
\hline
\end{tabular}

a Calculated according BET theory.

b Calculated using the BJH approach.

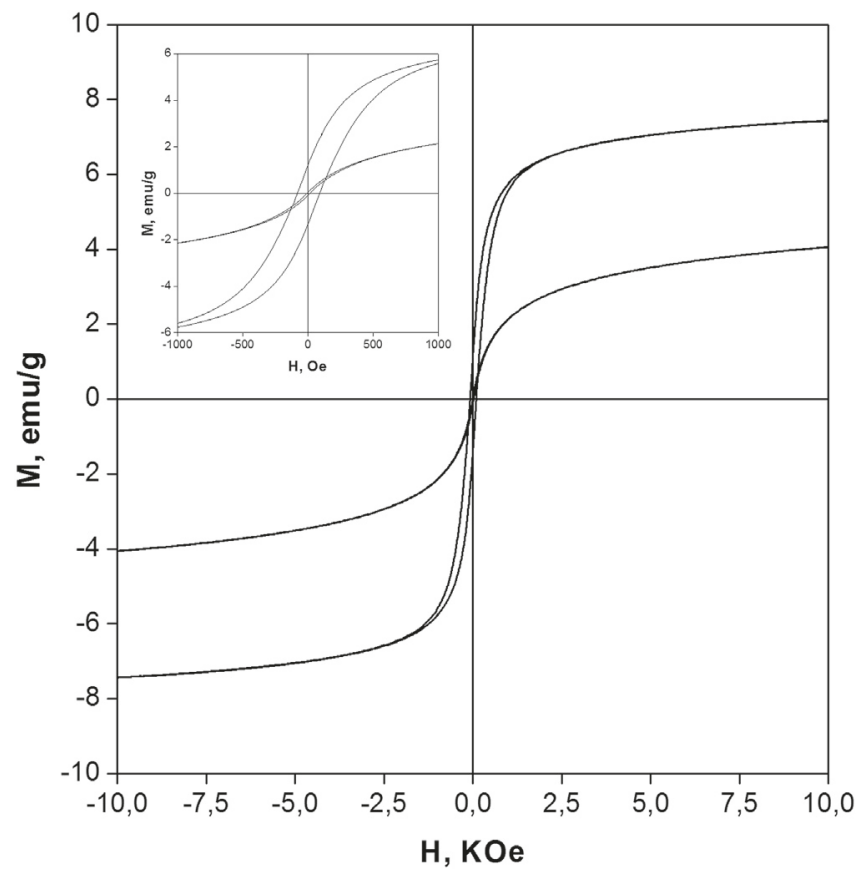

Fig. 5. Hysteresis loops for the ferrite:silica composites; annealed at $700{ }^{\circ} \mathrm{C}$ (a) and annealed at $900{ }^{\circ} \mathrm{C}$ (b).

Loadings were chosen in order to evaluate the effect of steadily increasing the concentration of the filler in the matrix until the maximal loading that enable processing of composites was attained $(25 \% \mathrm{w} / \mathrm{w})$, beyond this concentration the increased viscosity of the epoxy resin made degassing unmanageable. Fig. 6 shows as an example, representative images of the composites prepared with particles subjected at annealing at $900{ }^{\circ} \mathrm{C}$. The continuous dark phase corresponds to the epoxy matrix while polyhedral light grey regions correspond to the silica particles. The resolution of the images is not high enough to observe the ferrite nanoparticles, but very small spherical brighter features are intuited (Fig. 6). More over, no visible voids at the silica/epoxy interface were observed, indicating a good interaction between the particles and the matrix, and a homogeneous dispersion of the micro particles within the whole composite was achieved (Fig. 6). It is worth nothing that homogeneity of the micron sized silica dispersion in the matrix was observed by SEM even at very low magnifications and at the entire cross section of the sample. As the ferrite nanoparticles are constrained inside these micron sized particles, the micro homogeneity would imply that the ferrite particles are dispersed at the same extent than the micron sized silica particles in the polymer matrix, meaning that the nano dispersion has also been achieved by means of simple low energy mechanical mixing. Furthermore, despite having a low magnetic constituent loading and consequently, low saturation magnetization values (data not shown), all the prepared composites show a ferromagnetic behaviour when placed near an external magnetic field. The limi tation of processing composites with higher ferrite-silica concen trations may suggest that for EMI shielding applications, these materials may still be far from the expected EM behaviour because for most EMI shielding composites having magnetic nanoparticles as active constituents, the loading at which they start to be elec tromagnetically noticeable is almost above $50-70 \%(\mathrm{w} / \mathrm{w})$ $[38,55,56]$.

For further evaluation of the silica/epoxy interaction, the glass transition temperature ( $\mathrm{Tg}$ ) of the composites was determined by DSC. The values obtained for the composites are shown in Table 2 

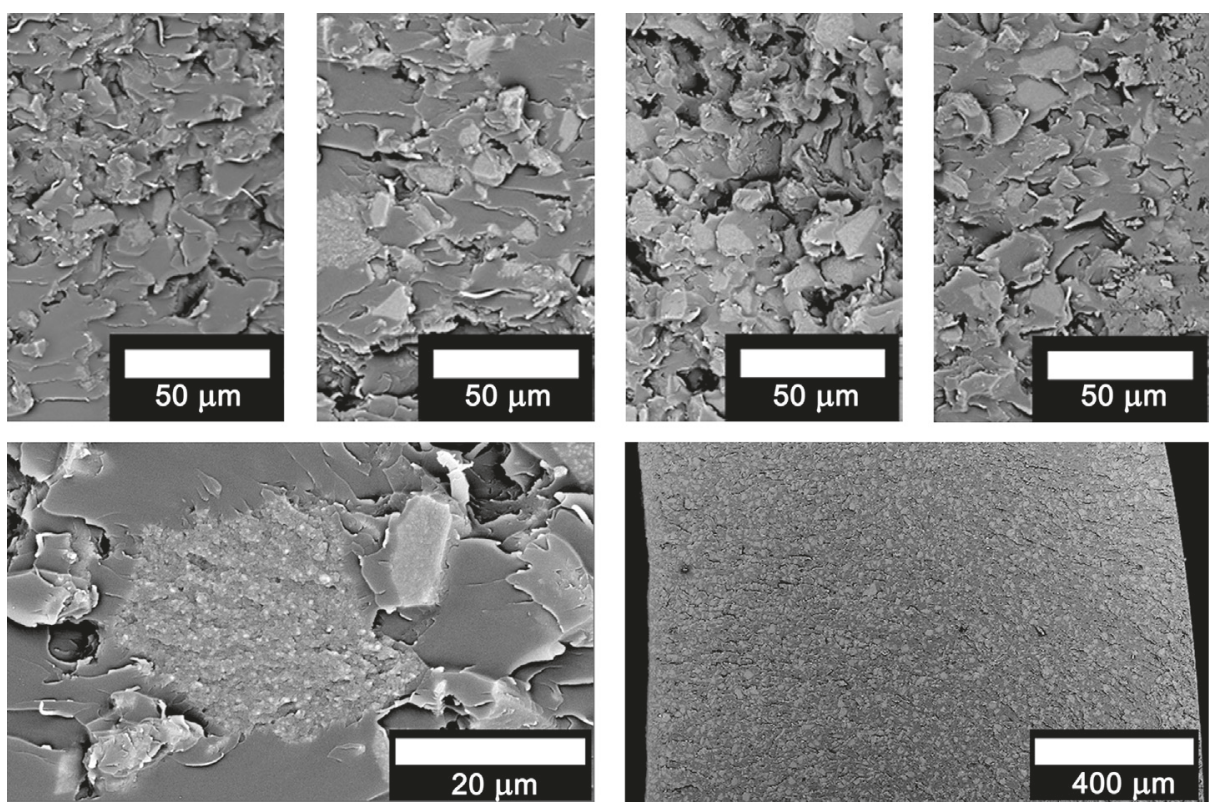

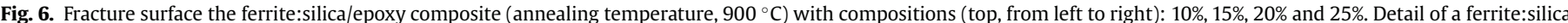
particle dispersed in the epoxy matrix (bottom left) and representative overview of the dispersion degree achieved (bottom right).

where it can be observed an increase in the $\mathrm{Tg}$ value for all the samples when compared with the neat epoxy. This effect has been previously reported for other polymer based composite materials at comparable inorganic filler loadings [57-59] and epoxy based composite materials with rough surface inorganic particles $[60,61]$, and has been attributed to a local reduction of free volume of the polymer chains nearby the filler surface due to an enhanced interaction between both phases. Accordingly, increasing the polymer/filler contact surface (high specific surface area fillers) may also contribute to hinder the polymer motion [62]. This observation is consistent with the increasing trend of the Tg for both ferrite:silica composites (with particles annealed at 700 or at $900{ }^{\circ} \mathrm{C}$ ) with the filler content up to $20 \%(\mathrm{w} / \mathrm{w})$, being more relevant in the case in which the ferrite:silica particles were annealed at $700{ }^{\circ} \mathrm{C}$ which showed a higher surface area.

Thermal stability of the composites was evaluated by TGA in air atmosphere (Fig. 7). None of the recorded thermograms showed hydration loses at low temperatures $\left(\leq 200{ }^{\circ} \mathrm{C}\right)$, which is a common problem observed for epoxy resins modified with hygroscopic fillers, such as silica [63], Furthermore, two weight loses were observed in all cases, as in many other epoxy based materials $[64,65]$. As reported elsewhere, these weight loses are related with the commonly accepted three step degradation mechanism of the epoxy network: First, at $\sim 240{ }^{\circ} \mathrm{C}$, homolytic cleavage without significant weight loss takes place and subsequently, a major weight loss is caused by the dehydration of the alcoxy groups, followed by the formation of double bonds. The final degradation step, occurring at about $530^{\circ} \mathrm{C}$, can be ascribed to the oxidation of the residual species formed after the thermal degradation in air

\section{Table 2}

Glass transitions temperatures for ferrite:silica/epoxy composites for particles annealed at $700{ }^{\circ} \mathrm{C}\left(\mathrm{Tg}_{700}\right)$ and at $900{ }^{\circ} \mathrm{C}\left(\mathrm{Tg}_{900}\right)$.

\begin{tabular}{lll}
\hline Filler, \% & $\operatorname{Tg}_{700},{ }^{\circ} \mathrm{C}$ & $\operatorname{Tg}_{900},{ }^{\circ} \mathrm{C}$ \\
\hline 0 & 215 & 215 \\
10 & 216 & 216 \\
15 & 220 & 217 \\
20 & 222 & 220 \\
25 & 221 & 218 \\
\hline
\end{tabular}

trough different reaction mechanisms involving radicals from the initial stages of degradation.

All hybrid composites were found to be stable at least up to $340{ }^{\circ} \mathrm{C}$ when evaluating the onset decomposition temperature (Table 3), which shifted towards higher temperatures when compared with the pure epoxy. Since several overlapping degra dation steps are observed, the integral procedure decomposition temperature (IPDT) seems to be a more appropriate parameter for investigating the global thermal stability of the composites [66]. According to Doyle et al. [67] the IPDT can be defined as:

$$
\text { IPDT } \quad A \cdot K\left(\begin{array}{ll}
T_{\mathrm{f}} & \left.T_{\mathrm{i}}\right)+T_{\mathrm{i}}
\end{array}\right.
$$

where $T_{\mathrm{i}}$ and $T_{\mathrm{f}}$ are the initial and final experimental temperatures respectively, $A$ is the ratio between the area below the experimental TGA curve and the total area of the graph, and $K$ represents the ratio
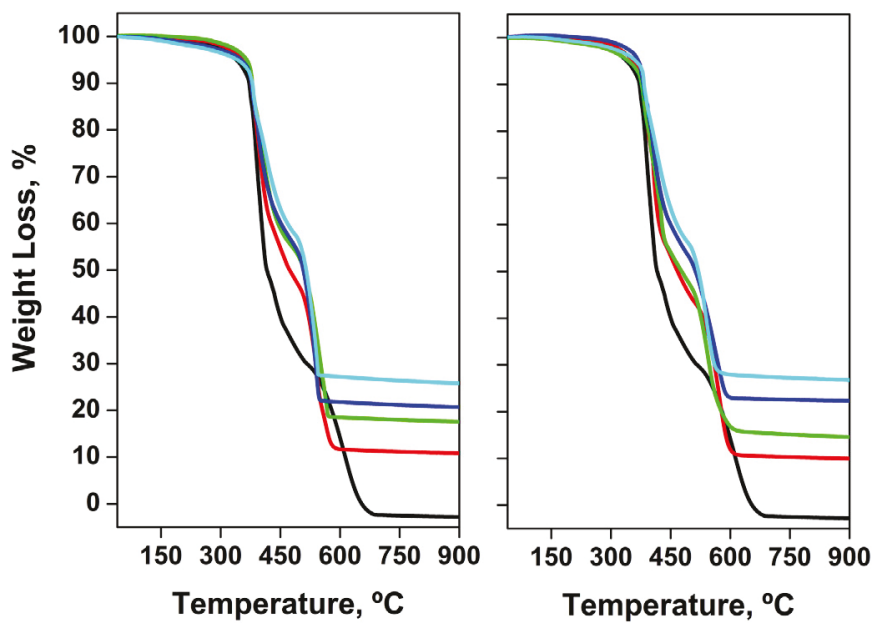

Fig. 7. Thermogravimetric analysis of the composites with ferrite:silica (left: annealed at $700{ }^{\circ} \mathrm{C}$; right: annealed at $900{ }^{\circ} \mathrm{C}$ ) at different loadings $0 \%$ (black), $10 \%$ (red), $15 \%$ (green), 20\% (dark blue) and 25\% (light blue). (For interpretation of the references to colour in this figure legend, the reader is referred to the web version of this article.) 
Table 3

T5\% and IPDT for the ferrite:silica/epoxy composites.

\begin{tabular}{|c|c|c|c|c|c|c|}
\hline \multirow[b]{2}{*}{ Filler, \% } & \multicolumn{3}{|c|}{ Particles synthesized at $700{ }^{\circ} \mathrm{C}$} & \multicolumn{3}{|c|}{ Particles synthesized at $900{ }^{\circ} \mathrm{C}$} \\
\hline & Residue, \% & $\mathrm{T} 5 \%,{ }^{\circ} \mathrm{C}$ & IPDT, ${ }^{\circ} \mathrm{C}$ & Residue, \% & $\mathrm{T} 5 \%,{ }^{\circ} \mathrm{C}$ & IPDT, ${ }^{\circ} \mathrm{C}$ \\
\hline $0 \%$ & & 340 & 316.2 & & 340 & 316.2 \\
\hline $10 \%$ & 10.8 & 358 & 410.9 & 10 & 357 & 404.9 \\
\hline $15 \%$ & 17.6 & 365 & 489.7 & 14.6 & 344 & 452.7 \\
\hline $20 \%$ & 20.7 & 351 & 529.4 & 22.4 & 369 & 554.3 \\
\hline $25 \%$ & 25.8 & 342 & 606.9 & 26.8 & 362 & 623.3 \\
\hline
\end{tabular}

between the area below the experimental curve and the area of the residual experimental curve:

$$
\text { A } \frac{S_{1}+S_{2}}{S_{1}+S_{2}+S_{3}}
$$

and

$$
K \quad \frac{S_{1}+S_{2}}{S_{2}}
$$

The IPDT values obtained are shown in Table 3. The evaluation of the IPDT showed that the thermal stability of the composites in creases with the content of the inorganic filler, independently of the type of filler (annealed at $700{ }^{\circ} \mathrm{C}$ or at $900{ }^{\circ} \mathrm{C}$ ). Although an improvement of the organic matrix thermal stability may be ex pected solely by the fact that silica has an inherent high thermal stability [68], the inhibition of the matrix decomposition during the calcination process has been also attributed to a mass transfer barrier effect of the insulating filler [69] and to an improved adhesion at the filler/matrix interphase [70]. This improvement is consistent with the Tg increment observed by DSC.

The reported findings may suggest that a less dense epoxy for mulations could eventually lead to composites with the same enhanced thermal stability, good reinforcement dispersion and magnetic response, but with higher ferrite concentrations and thus, being sufficiently magnetically active in order to serve as pro spective magnetic EMI shielding composites.

\section{Conclusions}

Mixed $\mathrm{Cu}-\mathrm{Ni}$ ferrites were synthesized in a mesoporous silica hard template using two annealing temperatures: $700{ }^{\circ} \mathrm{C}$ and $900{ }^{\circ} \mathrm{C}$. When increasing the annealing temperature, the size of the particles increases and the spinel structure remains unaltered. The nanoparticles prepared at $700{ }^{\circ} \mathrm{C}$ show a narrow size distribution with an average particle size close to 8.35 and a superparamagnetic behaviour, indicating that the nano scale control of the magnetic phase is feasible to achieve by the constraining effect of the silica template during its growth. When the annealing temperature was $900{ }^{\circ} \mathrm{C}$ a broader and nonsymmetric distribution was obtained, with diameters between 15 and $80 \mathrm{~nm}$ showing a non super paramagnetic behaviour. The incorporation of nanoferrite loaded silica particles in an epoxy matrix yielded a homogeneous micro scale distribution of particles in the matrix and still kept the magnetic nanoparticles independent.

The methodology proposed in this work for the manufacture of epoxy matrix composites, provides a way of controlling the nano and micro distribution of constituents, by which several re quirements are fulfilled: i) the magnetic properties are not affected by particle agglomeration; ii) the magnetic particles remain stable inside the silica pores; and iii) the silica provides an improvement in the thermal properties of the epoxy matrix.

Although composites with higher concentrations of ferrite-sil ica than the herein reported (maximal: $25 \%, \mathrm{w} / \mathrm{w}$ ) are needed in order to have materials with high EMI shielding ability, the pro posed methodology, that leads to materials having good epoxy reinforcement compatibility, enhanced thermal stability and superparamagnetic behaviour, could be extended to other epoxy formulations having less density and, consequently, having less limitations when incorporating higher ferrite-silica loadings.

\section{Acknowledgements}

This work was supported by, Nacopan (MAT2007 31173 E) and Nanomod (MAT2010 17091) from the Spanish Ministerio de Cien cia e Innovación.

\section{References}

[1] R. Hollertz, S. Chatterjee, H. Gutmann, T. Geiger, F.A. Nüesch, B.T.T. Chu, Nanotechnology 22 (2011) 125702125710.

[2] J.K.W. Sandler, J.E. Kirk, I.A. Kinloch, M.S.P. Shaffer, A.H. Windle, Polymer 44 (2003) 58935899.

[3] T. Adachi, M. Osaki, W. Araki, S. Kwon, Acta Mater. 56 (2008) 21012109.

[4] M. Conradia, M. Zorkob, A. Kocijana, I. Verpoestc, Mater. Chem. Phys. 137 (2013) 910915.

[5] S. Wei, Q. Wang, J. Zhu, L. Sun, H. Lin, Z. Guo, Nanoscale 3 (2011) 44744502.

[6] J. Gass, P. Poddar, J. Almand, S. Srinath, H. Srikanth, Adv. Funct. Mater. 16 (2006) 7175

[7] C. Albornoz, S.E. Jacobo, J. Magn. Magn. Mater. 3 (2006) 1215.

[8] X.L. Dong, X.F. Zhang, H. Huang, F. Zuo, Appl. Phys. Lett. 92 (2008) 013127 0131130.

[9] Q. He, T. Yuan, X. Zhang, Z. Luo, N. Haldolaarachchige, L. Sun, D.P. Young, S. Wei, Z. Guo, Macromolecules 46 (2013) 23572368.

[10] G.C. Papaefthymiou, Nano Today 4 (2009) 438447.

[11] A.H. Lu, E.L. Salabas, F. Schüth, Angew. Chem. Int. Ed. 46 (2007) 1222 1244.[12]

Q. He, T. Yuan, S. Wei, N. Haldolaarachchige, Z. Luo, D.P. Young, A. Khasanov, Z. Guo, Angew. Chem. Int. Ed. 51 (2012) 88428845.

[13] M.P. Pileni, J. Phys. Chem. 97 (1993) 69616973.

[14] Z. Yue, J. Zhou, L. Li, H. Zhang, Z. Gui, J. Magn. Magn. Mater. 208 (2000) 55 60.[15]

Q. He, T. Yuan, Z. Luo, N. Haldolaarachchige, D.P. Young, S. Wei, Z. Guo, Chem. Commun. 49 (2013) 26792681.

[16] A. Lu, F. Schüth, Adv, Mater. 18 (2006) 17931805.

[17] L.L. Hench, J.K. West, Chem. Rev. 90 (1990) 3372.

[18] L.A. García-Cerda, V.A. Torres-García, J.A. Matutes-Aquino, O.E. Ayala-Valenzuela, J. Alloys Compd. 369 (2004) 148151.

[19] A.B. Fuertes, J. Phys. Chem. Solids 66 (2005) 741747.

[20] M. Stoia, C. Caizer, M. Stef anescu, P. Barvinschi, L. Barbu-Tudoran, J. Sol-Gel Sci. Technol. 58 (2011) 126134

[21] T. Valdés-Solís, P. Tartaj, G. Marbán, A.B. Fuertes, Nanotechnology 18 (2007) 145603.

[22] Y. Naito, K. Suetake, IEEE Trans. Microwave Theory Tech. 19 (1971) 65 72.[23]

D.R. Patil, B.K. Chougule, Mater. Chem. Phys. 117 (2009) 3540.

[24] J.Z. Jiang, G.F. Goya, H.R. Rechenberg, J. Phys. Condens. Matter 11 (1999) 40634078.

[25] G.F. Goya, H.R. Rechenberg, Nanostruct. Mater. 10 (1998) 10011011

[26] G. Doh, E.B. Kim, B.H. Lee, J.H. Oh, J. Magn. Magn. Mater. 272276 (2004) 22382240.

[27] R. Dosoudil, M. U`sákov, J. Franek, J. Sláma, V. Olah, J. Magn. Magn. Mater. 304 (2006) e755 e757.

[28] X. Zhang, O. Alloul, J. Zhu, Q. He, Z. Luo, H.A. Colorado, N. Haldolaarachchige, D.P. Young, T.D. Shen, S. Wei, Z. Guo, RSC Adv. 3 (2013) 94539464.

[29] H. Gu, S. Tadakamalla, Y. Huang, H.A. Colorado, Z. Luo, N. Haldolaarachchige, D.P. Young, S. Wei, Z. Guo, ACS Appl. Mater. Interfaces 4 (2012) 5613 5624.[30]

J. Zhu, S. Wei, J. Ryu, L. Sun, Z. Luo, Z. Guo, ACS Appl. Mater. Interfaces 2 (2010) 21002107.

[31] Z. Guo, K. Lei, Y. Li, H.W. Ng, S. Prikhodko, H.T. Hahn, Compos. Sci. Technol. 68 (2008) 15131520

[32] L.A. Ramajo, A.A. Cristóbal, P.M. Botta, J.M. Porto-López, M.M. Reboredo, M.S. Castro, Compos. Part A 40 (2009) 388393.

[33] B. Hallouet, B. Wetzel, R. Pelster, J. Nanomater. 2007 (2007) 34527 34538.[34]

G. Kortaberria, P. Arruti, A. Jimeno, I. Mondragón, M. Sangermano, J. Appl. Polym. Sci. 109 (2008) 32243229.

[35] M. González, I. Martín-Fabiani, J. Baselga, J. Pozuelo, Mater. Chem. Phys. 132 (2012) 618624

[36] J. Zhu, S. Wei, I.Y. Lee, S. Park, J. Willis, N. Haldolaarachchige, D.P. Young, Z. Luo, Z. Guo, RSC Adv. 2 (2012) 11361143

[37] M. Chen, H. Qu, J. Zhu, Z. Luo, A. Khasanov, A.S. Kucknoor, Polymer 53 (2012) 45014511.

[38] J. .Zhu, S. Wei, N. Haldolaarachchige, D.P. Young, Z. Guo, J. Phys. Chem. C. 115 (2011) 1530415310.

[39] X. Guo, Y. Deng, D. Gu, R. Che, D. Zhao, J. Mater. Chem. 19 (2009) 67066712

[40] C.L. Chiang, C.S. Sung, C.Y. Chen, J. Magn. Magn. Mater. 305 (2006) 483490. 
[41] L.C.A. Oliveira, R.V.R.A. Rios, J.D. Fabrisa, V. Garg, K. Sapag, R.M. Lago, Carbon 40 (2002) 21772183.

[42] Y. Park, T. Kang, Y.S. Cho, P. Kim, J.C. Park, J. Yi, Stud. Surf. Sci. Catal. 146 (2003) 637640.

[43] I. Park, H. Peng, D.W. Gidley, S. Xue, T.J. Pinnavaia, Chem. Mater. 18 (2006) 650656.

[44] M.A.B. Meador, E.F. Fabrizio, F. Ilhan, A. Dass, G. Zhang, P. Vassilaras, J.C. Johnston, N. Leventis, Chem. Mater. 17 (2005) 10851098.

[45] Safety Data Sheet RTM6 Hexcel Composites, Duxford, UK.

[46] Y. Jia, W. Han, G. Xiong, W. Yang, Sci. Technol. Adv. Mater. 8 (2007) 106109.

[47] B. Folch, J. Larionova, Y. Guari, L. Datas, C. Guérin, J. Mater. Chem. 16 (2006) 44354442.

[48] V.M. Gun'ko, R. Leboda, J. Skubiszewska-Zie،ba, V.V. Turov, P. Kowalczyk, Langmuir 17 (2001) 31483161

[49] Z. Li, C. Liu, Q. Zhao, J. Non-Cryst. Solids 265 (2000) 189192.

[50] C.J. Brinker, K.D. Keefer, D.W. Schaefer, C.S. Ashley, J. Non-Cryst. Solids 48 177190. (1982) $47 \quad 64$

[51] R. Köhn, M. Fröba, Catal. Today 68 (2001) 227236.

[52] A.B. Fuertesa, D.M. Nevskaia, Microporous Mesoporous Mater. 62 (2003) 385226.

[53] R. Hergt, S. Dutz, M. Röder, J. Phys. Condens. Matter 20 (2008) 385214
[54] H.V. Kiran, A.L. Shashimohan, D.K. Chakrabarty, A.B. Biswas, Phys. Status Solidi A 66 (1981) 743747.

[55] M. Wu, Y.D. Zhang, S. Hui, T.D. Xiao, S. Ge, W.A. Hines, J.I. Budnick, G.W. Taylor, Appl. Phys. Lett. 80 (2002) 44044406.

[56] X.F. Zhang, X.L. Dong, H. Huang, Y.Y. Liu, W.N. Wang, X.G. Zhu, B. Lv, J.P. Lei, C.G. Lee, Appl. Phys. Lett. 89 (2006) 053115053117

[57] M. Preghenella, A. Pegoretti, C. Migliaresi, Polymer 46 (2005) 1206512072.

[58] X. Ji, J.E. Hampsey, Q. Hu, J. He, Z. Yang, Y. Lu, Chem. Mater. 15(2003) 36563662

59] K. Moller, T. Bein, R.X. Fischer, Chem. Mater. 10 (1998) 18411852.

60] N. Kudo, T. Masuko, J. Appl. Polym. Sci. 69 (1998) 25932598.

61] S.C. Kwon, T. Adachi, W. Araki, A. Yamaji, Acta Mater. 54 (2006) 33693374

[62] Y. lhnaka, Y. Nakahara, K. Lhkemoto, Angew. Makromol. Chem. 191 (1991) 7180.

[63] O. Becker, R.J. Varley, G.P. Simon, Eur. Polym. J. 40 (2004) 187195.

[64] J.C. Patterson-Jones, J. Appl. Polym. Sci. 19 (1975) 15391547.

[65] N. Grassie, M.I. Guy, N.H. Tennent, Polym. Degrad. Stab. 14 (1986) 125137.

66] Y.L. Liu, W.L. Wei, K.Y. Hsu, W.H. Ho, Thermochim. Acta 412 (2004) 139147.

67] C.D. Doyle, Anal. Chem. 33 (1961) 7779.

[68] J.Y. Wen, G.L. Wilkes, Chem. Mater. 8 (1996) 16671681

[69] J. Macan, I. Brnardi 'c, S. Orli 'c, H. Ivankovi 'c, M. Ivankovi\&cacute, Polym. Degrad. Stab. 91 (2006) 122127.

[70] S.J. Park, M.S. Cho, J. Mater. Sci. 35 (2000) 35253527. 